\title{
COMPARATIVE STUDY OF LONG- AND SHORT-STRETCH WOVEN COMPRESSION BANDAGES
}

\author{
Abdelhamid R. R. Aboalasaad ${ }^{1, *}$, Brigita Kolčavová Sirková1, Pavlína Bílá1, Amany A. S. Khalil² \\ 1 Technologies and Structures Department, Technical University of Liberec, Liberec 46117, Czech Republic \\ 2 Department of Textile Evaluation, Technical University of Liberec, Liberec 46117, Czech Republic \\ ${ }^{*}$ Corresponding author. Email: eabdo6@gmail.com
}

\begin{abstract}
:
Compression therapy using bandages or socks is the most common treatment for venous leg ulcers and edema. This article aims to compare the compression between long- and short-stretch bandages (LSB and $S S B$, respectively). Load-elongation curves, cyclic loading, and elastic recovery are investigated for both Cotton/ Polyamide/Polyurethane and $100 \%$ bleached cotton bandages as LSB and SSB, respectively. Static (resting) and dynamic (working) pressures are measured on seven male legs, $31 \pm 3.6$ years old, using both two and three layers bandaging. Picopress pressure tests are performed on the ankle and mid-calf positions at gradual decreasing compression from the ankle to the knee. The deviation percentage between the experimental results by Picopress and theoretical calculations using Laplace's law and Al-Khaburi equations is compared. LSB recovered approximately $99 \%$ of its original length after stress-relaxation whereas SSB recovered only $93 \%$ of its original length after 5 days of cyclic load-relaxation. Moreover, SSB lost approximately $28.6 \%$ of its activity after wearing on the human leg for 5 days.
\end{abstract}

\section{Keywords:}

Compression therapy, long and short-stretch woven compression bandages, Picopress tester, stress-relaxation, cyclic loading

\section{Introduction}

\subsection{Definition and application of long and short-stretch compression bandages}

Long-stretch bandage (LSB) can be defined as "an elastic compression bandage (CB) that contains elastic filament (rubber, Lycra, or elastane) which allows the bandage to stretch more than $120 \%$ of its original length"; it can be applied smoothly and conformed according to the contour of the human leg. According to the level of compression applied by the LSB, it might be essential to take it off at night because the resting (static) pressure when sleeping is annoying. Short-stretch bandage (SSB) can be defined as "elastic CB, however, is composed of cotton yarns, but usually it's highly twisted yarns $(1,200-2,300$ turns/m) [1], these yarns are interwoven to enable the bandage's original length to be extended by almost 60 $70 \%$ during application." The main advantage of these shortstretch compression bandages (CBs) is that they achieve high working pressure which is necessary for lymphatic drainage and venous flow [2-7].

Static Stiffness Index (SSI) is defined as the difference between the interface pressures when someone is standing or lying $(\mathrm{mmHg})$ divided by $1 \mathrm{~cm}$. LSB has a value of SSI $<10$ while SSB has a value of SSI >10. The pressure peaks at walking action are slightly higher than for standing conditions [8].

\subsection{Production methods and structures of long and short- stretch CBs}

The main function of SSB is to provide graduated pressure on the lower limb decreasing from the ankle to the knee to improve venous return, accelerate the venous flow, reduce venous reflux by realignment of valves, improve venous pump action, and reduce edema [8, 9]. On the other hand, LSB is not suitable for lymphedema management because it has low working pressure. This low pressure does not offer adequate resistance, and fluid would inevitably accumulate. In addition, the high resting pressure of LSB could constrict veins and lymph vessels during rest or sleep [10]. There are three methods for producing woven compression bandages (WCBs) to achieve the optimum stretch. The first method is using highly twisted warp yarns and the resultant bandage in this case is SSB. The second method is elastane (Polyurethane) filament with Viscose (VI) or Cotton (CO) to produce LSB. The third method is two polymeric yarns with different melting points by steaming and heat setting; usually, it is SSB $[1,11,12]$.

\subsection{Advantages of long and short-stretch CBs}

Short-stretch CBs are made using stiff materials that enable them to achieve the optimum balance between working and resting pressures. They create high working pressure on the ankle and calf muscles due to the interaction between the 
lower leg and CB during any activity or walking action. This SSB compresses the muscles by irregular intervals, oscillating between high and low pressures. The resultant oscillations form an internal pumping action that shifts fluid out of the tissues and returns to the vessels of the lymphatic system. Moreover, it achieves low resting pressure on relaxed muscles, static state, or sleeping. This low resting pressure, when the muscles are inactive, enables reducing the spaces in tissues where fluid can leak in that means they could be worn day and night and are tolerated well by the patient $[13,14]$.

Wearing LSB increased pressure by $8 \mathrm{mmHg}$ for standing position, while using SSB had a significant increase by $25 \mathrm{mmHg}$ and higher working pressure [15]. Two studies found that SSB is superior in healing venous ulcers and reducing venous reflux over LSB $[16,17]$. Moreover, some others proved that short-stretch and Unna's boot were found to support the pump function better than long-stretch CBs (evidence level A) $[18,19]$. LSB can sustain its pressure up to 1 week due to its ability to accommodate changes in the shape and movement of the limb. SSB can be effective for 2-3 days because of a significant reduction in edema. When the patient is mobile, SSB is more effective because of the calf muscle contracts against the wrap which forces blood toward the heart. Patients with mixed arterial/venous insufficiency can better tolerate SSB because it has lower resting pressure $[20,21]$. SSB tends to generate lower resting pressures but the pressure increases with walking due to calf muscle expansion. It is therefore ideal for mobile patients. SSB should be reapplied once edema has improved. Increased layers not only augment the pressure applied but also tend to render the compression less elastic [22].

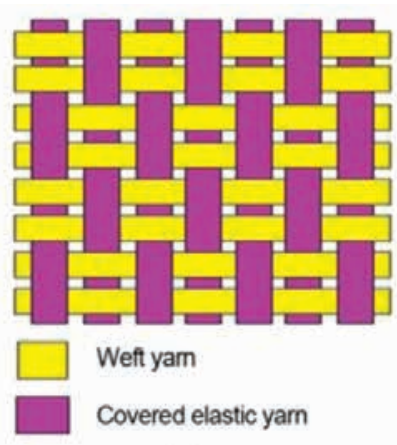

(a)

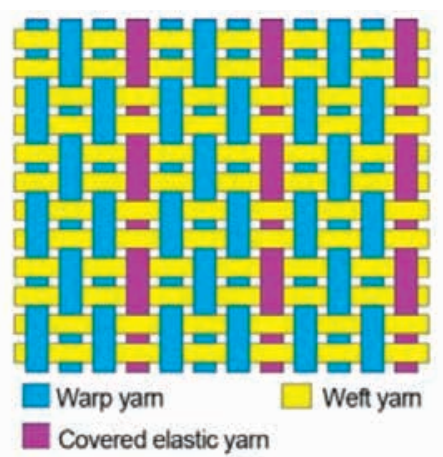

(b)
Figure 1. Structure of woven bandages based on the plain weave and elastane [11].

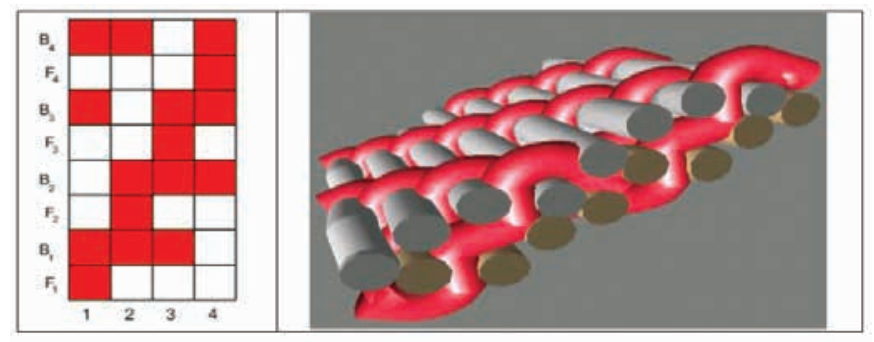

Figure 2. Double weft fabric structure based on Twill weave $1 / 3$, highly twisted warp yarns [12].
Few studies focused on the optimization and best combinations of CBs for venous leg ulcers, edema healing, and prevention of recurrence. Most patients depend on specialist practitioners or traditional experience. The motivation of this research is to investigate the optimum conditions for compression therapy using long- and short-stretch WCBs. The methodology is based on evaluating the elastic recovery of both bandages during cyclic loading-unloading to simulate the real activities of the patient or athletic performance during rest and walking.

\section{Experimental work}

\subsection{Materials}

Cotton/Polyamide/Polyurethane (CO-PA-PU) and 100\% bleached Cotton WCBs were selected to represent long- and short-stretch WCBs, respectively, meanwhile the mechanical and bandage pressure properties were tested and compared. The planar structures of selected WCBs are illustrated in Figure 3.

\subsection{Testing procedure}

\subsubsection{Load-elongation test for Cotton SSB and CO-PA-PU LSB}

The Stress-relaxation test has a priority during the WCB application to create the optimum pressure on the patient leg during the whole treatment period. Cyclic loading-unloading of WCB is investigated based on the standard test method ISO 13934-1:1999(E) [23, 24]. Testometric M350-5CT is used to evaluate the applied tension by WCB when extending the bandage sample by $60 \%$ and $120 \%$ of its original gauge length $(5 \mathrm{~cm})$ using constant traverse speed of $100 \mathrm{~mm} / \mathrm{min}$ [24]. The digital camera is used while tensile and cyclic loading-unloading of the WCBs; testing details are illustrated in Figure 5.

\subsubsection{Testing of bandage pressure using Picopress}

All selected WCB types were worn on the human leg to measure the bandage pressure by Picopress at the ankle and mid-calf positions while walking [1].

It is important to give the patient, nurse, or other bandage user clear guidelines for CB application. So, it is possible to predict the required bandage pressure as a function of applied tension or extension, see Figure 4 [25, 26].

\subsubsection{Validation of measured pressure using two mathematical models}

For validation of WCBs pressure, the measured results using Picopress were compared with theoretical pressure calculated by Laplace's Equation (2) and Al Khaburi's Equation (4) as follows [26, 28-30]: 


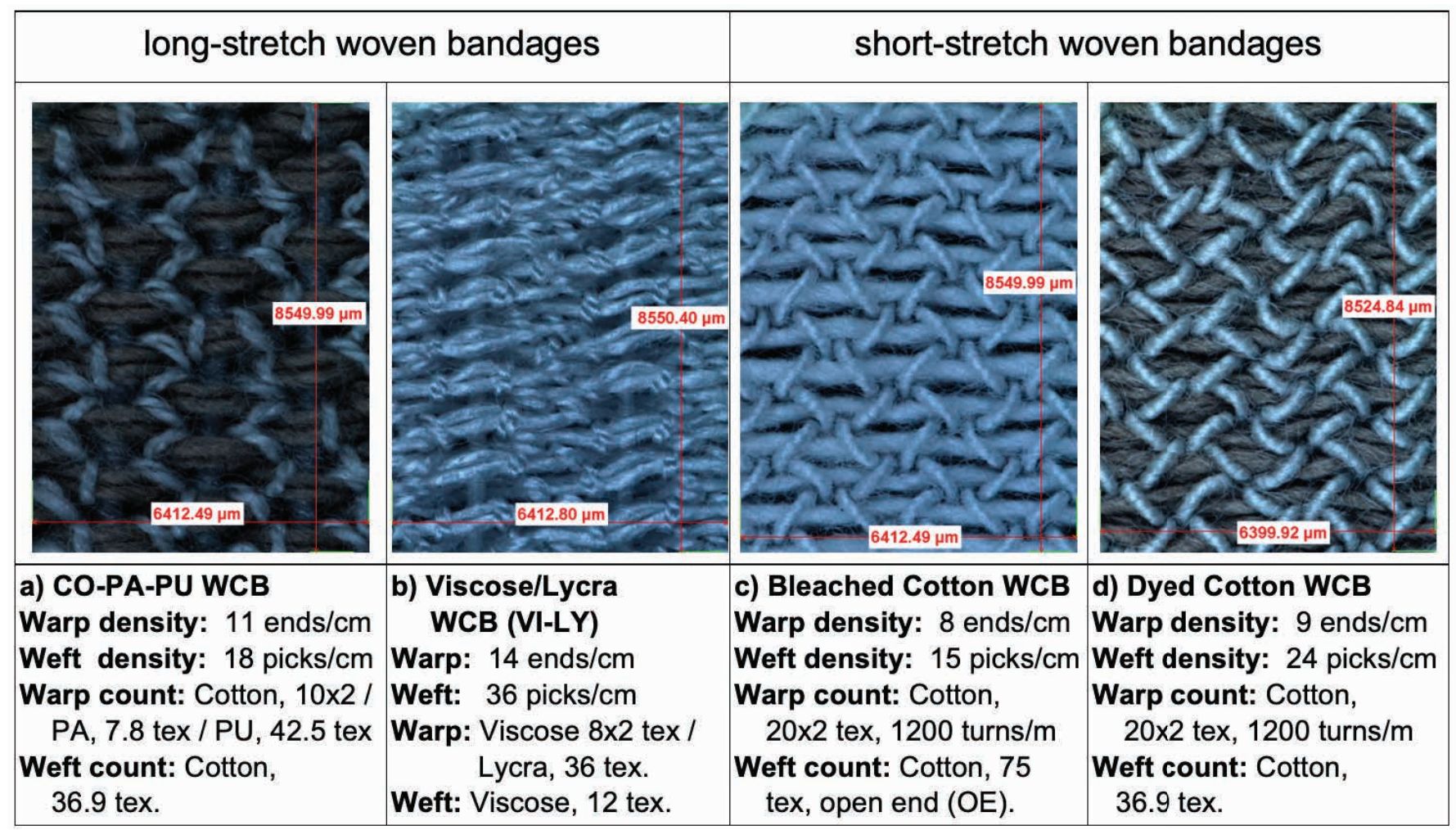

Figure 3. Long- and short-stretch-woven compression bandages parameters.

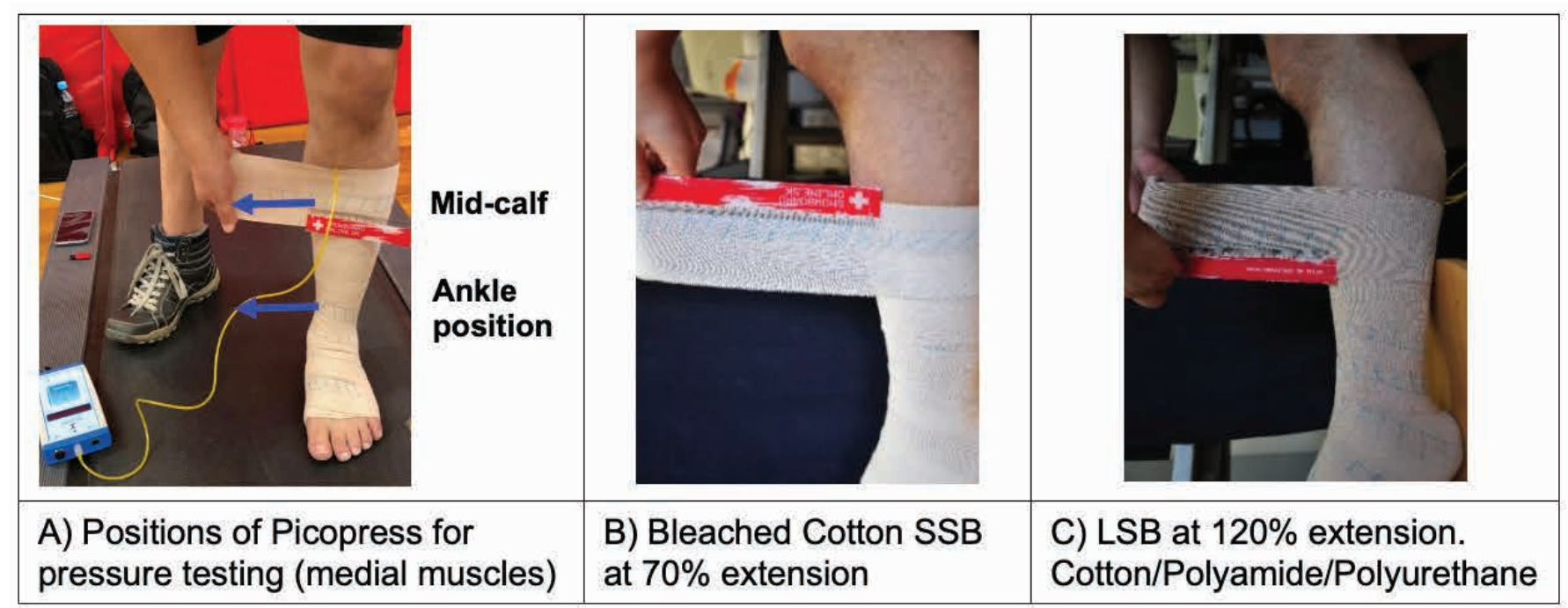

Figure 4. Positions and guide marks for bandage applications [27].

Pressure $($ Pascal $)=\frac{\text { Tension }(\mathrm{N}) * \text { No. of Layers }}{\text { Radius }(\mathrm{m}) * \text { Bandage width }(\mathrm{m})}$

Pressure $(\mathrm{mmHg})=\frac{\mathrm{T}(\mathrm{N}) * \mathrm{n}}{\mathrm{R}(\mathrm{m}) * \mathrm{~W}(\mathrm{~m})} * 0.0075$

The bandage pressure could be mathematically calculated by Laplace's equation which states that the pressure ( $\mathrm{P}$ measured in $\mathrm{Pa}$ ) applied to the skin surface is directly proportional to the bandage tension $(T, N)$ and the number of wraps, and inversely proportional to the radius of limb circumference $(R, m)$ and bandage width $(\mathrm{W}, \mathrm{m})[26,31]$.

\subsubsection{Tensile and cyclic loading-unloading test}

Optimization of the applied tension during bandage application at specified extension ranges is illustrated as summarized in Tables 1 and 2. 


\begin{tabular}{|c|c|c|}
\hline Action of bandage test & CO-PA-PU WCB \\
\hline $\begin{array}{c}\text { Sample size } 10 \times 10 \mathrm{~cm}^{2}, \\
\text { original gauge length } 5 \mathrm{~cm}\end{array}$ \\
\hline $\begin{array}{c}\text { Elongation by } 3 \mathrm{~cm} ; \\
\text { extension by } 60 \% \text {, then } \\
\text { relaxation } 1 \mathrm{~cm} \text { that } \\
\text { extension becomes } 40 \%, \\
\text { then again extension } 60 \% \\
\text { for } 6 \text { cycles }\end{array}$ \\
\hline $\begin{array}{c}\text { After } 6 \text { cycles of loading- } \\
\text { unloading }\end{array}$
\end{tabular}

Figure 5. Testing of tensile and cyclic loading-unloading by Testometric M350-5CT.

\section{Results and discussions}

\subsection{Load-elongation curves for Cotton SSB and CO-PA-PU $\underline{\text { LSB }}$}

Cotton and CO-PA-PU WCBs were subjected to tensile stress by $60 \%$ extension of its original length; cotton bandage achieved $10.3 \mathrm{~N}$, whereas CO-PA-PU had only $5.31 \mathrm{~N}$ at the same extension. When the CO-PA-PU bandage was extended to $120 \%$; it had achieved approximately $14.15 \mathrm{~N}$, see Figure 6 . These results are matched with some other experimental studies [1, 25].

\subsection{Effect of bandage extension on corresponding pressure for WCBs}

Bandage pressures using Picopress were evaluated during the Cotton and CO-PA-PU WCBs application for ankle and midcalf position using two and three wraps bandaging techniques. Figure 7 illustrates that Cotton SSB exerted medium pressure of 21.71 and $32.67 \mathrm{mmHg}$ on ankle position at $50 \%$ extension for two and three layers, respectively, while 14.21 and $20.92 \mathrm{mmHg}$ on mid-calf position. Moreover, high pressure
45.71 and $68.38 \mathrm{mmHg}$ on the ankle, 30.85 and $44.21 \mathrm{mmHg}$ on mid-calf positions achieved at $70 \%$ extension, see Tables 1 and $2[1,32]$.

As for long-stretch CO-PA-PU CB, medium pressure of 20.13 and $30.49 \mathrm{mmHg}$ on ankle position at $60 \%$ extension, whereas 13.28 and $20.63 \mathrm{mmHg}$ on mid-calf position, as shown in Figure 8. Moreover, high pressure 47.93 and $71.69 \mathrm{mmHg}$ on the ankle, 33.15 and $45.94 \mathrm{mmHg}$ on mid-calf positions achieved at $120 \%$ extension, see Tables 1 and 2 .

\subsection{Effect of bandage tension on resultant pressure for WCBs}

Figures 9 and 10 display the corresponding working pressure as a function of bandage tension for short-stretch Cotton and long-stretch CO-PA-PU bandages, respectively. Medium pressure of $35.19 \mathrm{mmHg}$ at ankle position can be achieved at $9.79 \mathrm{~N}$ using two layers of cotton bandage while high pressure of $68.38 \mathrm{mmHg}$ at $13.85 \mathrm{~N}$ can be achieved through three layers. On the other hand, CO-PA-PU can achieve $32.15 \mathrm{mmHg}$ at $8.64 \mathrm{~N}$ and $71.69 \mathrm{mmHg}$ at $14.23 \mathrm{~N}$ using two and three layers, respectively $[1,33]$. 
Table 1. Measured compression using Picopress versus calculated pressure by mathematical models at ankle position

\begin{tabular}{|c|c|c|c|c|c|c|c|c|c|}
\hline \multirow{2}{*}{$\begin{array}{l}\text { Bandage } \\
\text { type }\end{array}$} & \multirow{2}{*}{$\begin{array}{l}\text { No of } \\
\text { layers }\end{array}$} & \multirow{2}{*}{$\begin{array}{c}\text { Extension } \\
(\%)\end{array}$} & \multirow{2}{*}{$\begin{array}{c}\text { Applied } \\
\text { tension }(\mathbf{N})\end{array}$} & \multirow{2}{*}{$\begin{array}{l}\text { SD of } \\
\text { tension }\end{array}$} & \multirow{2}{*}{$\begin{array}{c}\text { Measured } \\
\text { compression } \\
\text { by Picopress } \\
(\mathrm{mmHg})\end{array}$} & \multicolumn{4}{|c|}{ Calculated pressure values $(\mathrm{mmHg})$} \\
\hline & & & & & & $\begin{array}{l}\text { Laplace's } \\
\text { equation }\end{array}$ & $\begin{array}{c}\text { Deviation } \\
\text { percent (\%) }\end{array}$ & $\begin{array}{c}\text { Al-Khaburi } \\
\text { equation }\end{array}$ & $\begin{array}{c}\text { Deviation } \\
\text { percent }(\%)\end{array}$ \\
\hline \multirow{14}{*}{$\begin{array}{c}\text { Short- } \\
\text { stretch } \\
100 \% \\
\text { cotton } \\
\text { bandage }\end{array}$} & \multirow{7}{*}{2} & 20 & 1.75 & 0.19 & 7.02 & 6.45 & -8.84 & 6.29 & -11.52 \\
\hline & & 30 & 2.81 & 0.07 & 10.84 & 10.36 & -4.67 & 10.11 & -7.24 \\
\hline & & 40 & 3.94 & 0.12 & 14.62 & 14.52 & -0.68 & 14.17 & -3.16 \\
\hline & & 50 & 6.06 & 0.31 & 21.71 & 22.33 & 2.79 & 21.80 & 0.41 \\
\hline & & 60 & 9.79 & 0.82 & 35.19 & 36.08 & 2.47 & 35.22 & 0.07 \\
\hline & & 70 & 13.37 & 1.41 & 45.71 & 49.28 & 7.24 & 48.09 & 4.96 \\
\hline & & 80 & 17.26 & 1.92 & 56.83 & 63.61 & 10.66 & 62.09 & 8.47 \\
\hline & \multirow{7}{*}{3} & 20 & 1.8 & 0.22 & 10.58 & 9.95 & -6.32 & 9.60 & -10.22 \\
\hline & & 30 & 2.92 & 0.11 & 16.39 & 16.14 & -1.53 & 15.57 & -5.25 \\
\hline & & 40 & 4.05 & 0.17 & 21.83 & 22.39 & 2.50 & 21.60 & -1.07 \\
\hline & & 50 & 6.24 & 0.39 & 32.67 & 34.50 & 5.29 & 33.28 & 1.83 \\
\hline & & 60 & 10.12 & 0.94 & 51.61 & 55.95 & 7.75 & 53.97 & 4.37 \\
\hline & & 70 & 13.85 & 1.55 & 68.38 & 76.57 & 10.69 & 73.86 & 7.42 \\
\hline & & 80 & 17.93 & 2.13 & 83.62 & 99.12 & 15.64 & 95.62 & 12.55 \\
\hline \multirow{12}{*}{$\begin{array}{c}\text { Long- } \\
\text { stretch } \\
\text { CO-PA-PU } \\
\text { bandage }\end{array}$} & \multirow{6}{*}{2} & 20 & 1.41 & 0.19 & 5.57 & 5.20 & -7.19 & 5.07 & -9.82 \\
\hline & & 40 & 3.58 & 0.13 & 13.81 & 13.19 & -4.67 & 12.88 & -7.24 \\
\hline & & 60 & 5.25 & 0.21 & 20.13 & 19.35 & -4.04 & 18.88 & -6.59 \\
\hline & & 80 & 8.64 & 0.49 & 32.15 & 31.84 & -0.96 & 31.08 & -3.45 \\
\hline & & 100 & 10.73 & 0.73 & 41.62 & 39.55 & -5.25 & 38.60 & -7.83 \\
\hline & & 120 & 13.97 & 1.65 & 47.93 & 51.49 & 6.91 & 50.25 & 4.62 \\
\hline & \multirow{6}{*}{3} & 20 & 1.43 & 0.18 & 8.35 & 7.91 & -5.62 & 7.63 & -9.49 \\
\hline & & 40 & 3.64 & 0.15 & 21.06 & 20.12 & -4.66 & 19.41 & -8.49 \\
\hline & & 60 & 5.37 & 0.19 & 30.49 & 29.69 & -2.71 & 28.64 & -6.47 \\
\hline & & 80 & 8.91 & 0.53 & 46.43 & 49.26 & 5.74 & 47.52 & 2.29 \\
\hline & & 100 & 10.94 & 0.97 & 56.39 & 60.48 & 6.76 & 58.34 & 3.35 \\
\hline & & 120 & 14.23 & 2.19 & 71.69 & 78.67 & 8.87 & 75.89 & 5.53 \\
\hline
\end{tabular}

3.4. Effect of cyclic loading-unloading on bandage tension and durability

Two types of WCB (100\% Cotton SSB and CO-PA-PU LSB) were selected to investigate the relation between cyclic loading and the applied bandage load at $60 \%$ and $120 \%$ extension. Elongation by $3 \mathrm{~cm}$ results in extension by $60 \%$ and dwell time for $2 \mathrm{~s}$, then unloading $1 \mathrm{~cm}$ reduces extension by $40 \%$ and dwell time for $2 \mathrm{~s}$, then repeating the whole cycle for five or six repeats, and then relaxation. Cyclic loading-unloading could simulate the walking action wearing WCB, but the main obstacle is that the testing time is limited compared with bandage application. The uniaxial load of Cotton SSB decreased by $11.82 \%$ after six cycles of loading-unloading, whereas CO-PA-PU LSB lost only $4.81 \%$ of its applied load at $60 \%$ extension. Moreover, CO-PA-PU lost $18.11 \%$ at $120 \%$ extension, see Figure 9. Therefore, it is essential to include and compensate these reductions of bandage tension during its selection and application.

\subsection{Comparison between the calculated and measured pressures}

A $100 \%$ of Cotton and CO-PA-PU WCBs were worn on the human limb to test the real compression at the ankle and mid-calf positions in both resting and walking actions. The deviation percentage was calculated as a function of measured compression by Picopress and calculated pressure by Laplace's law, see Eq. (3). 
Table 2. Calculated pressure versus measured compression values at mid-calf position

\begin{tabular}{|c|c|c|c|c|c|c|c|c|c|}
\hline \multirow[b]{2}{*}{$\begin{array}{l}\text { Bandage } \\
\text { type }\end{array}$} & \multirow[b]{2}{*}{$\begin{array}{l}\text { No of } \\
\text { layers }\end{array}$} & \multirow[b]{2}{*}{$\begin{array}{c}\text { Extension } \\
(\%)\end{array}$} & \multirow[b]{2}{*}{$\begin{array}{c}\text { Applied } \\
\text { tension }(\mathbf{N})\end{array}$} & \multirow[b]{2}{*}{$\begin{array}{l}\text { SD of } \\
\text { tension }\end{array}$} & \multirow{2}{*}{$\begin{array}{c}\text { Measured } \\
\text { compression } \\
\text { by PicoPress } \\
(\mathrm{mmHg})\end{array}$} & \multicolumn{4}{|c|}{ Calculated pressure values $(\mathrm{mmHg})$} \\
\hline & & & & & & $\begin{array}{l}\text { Laplace's } \\
\text { equation }\end{array}$ & $\begin{array}{c}\text { Deviation } \\
\text { percent } \\
(\%)\end{array}$ & $\begin{array}{c}\text { Al-Khaburi } \\
\text { equation }\end{array}$ & $\begin{array}{c}\text { Deviation } \\
\text { percent } \\
(\%)\end{array}$ \\
\hline \multirow{14}{*}{$\begin{array}{c}\text { Short- } \\
\text { stretch } \\
100 \% \\
\text { cotton } \\
\text { bandage }\end{array}$} & \multirow{7}{*}{2} & 20 & 1.71 & 0.19 & 4.61 & 4.14 & -11.25 & 4.08 & -13.05 \\
\hline & & 30 & 2.74 & 0.07 & 7.13 & 6.64 & -7.38 & 6.53 & -9.12 \\
\hline & & 40 & 3.82 & 0.12 & 9.5 & 9.26 & -2.63 & 9.11 & -4.28 \\
\hline & & 50 & 5.89 & 0.31 & 14.21 & 14.27 & 0.44 & 14.05 & -1.17 \\
\hline & & 60 & 9.55 & 0.82 & 23.08 & 23.14 & 0.27 & 22.77 & -1.34 \\
\hline & & 70 & 13.15 & 1.41 & 30.85 & 31.87 & 3.19 & 31.36 & 1.62 \\
\hline & & 80 & 16.86 & 1.92 & 37.75 & 40.86 & 7.60 & 40.21 & 6.11 \\
\hline & \multirow{7}{*}{3} & 20 & 1.76 & 0.22 & 7.08 & 6.40 & -10.67 & 6.25 & -13.34 \\
\hline & & 30 & 2.83 & 0.11 & 10.73 & 10.29 & -4.31 & 10.04 & -6.83 \\
\hline & & 40 & 3.97 & 0.17 & 14.11 & 14.43 & 2.22 & 14.09 & -0.14 \\
\hline & & 50 & 6.11 & 0.39 & 20.92 & 22.21 & 5.80 & 21.69 & 3.53 \\
\hline & & 60 & 9.85 & 0.94 & 33.47 & 35.80 & 6.52 & 34.96 & 4.26 \\
\hline & & 70 & 13.46 & 1.55 & 44.21 & 48.93 & 9.64 & 47.77 & 7.46 \\
\hline & & 80 & 17.41 & 2.13 & 54.97 & 63.28 & 13.14 & 61.79 & 11.04 \\
\hline \multirow{12}{*}{$\begin{array}{c}\text { Long- } \\
\text { stretch } \\
\text { CO-PA-PU } \\
\text { bandage }\end{array}$} & \multirow{6}{*}{2} & 20 & 1.39 & 0.19 & 3.75 & 3.37 & -11.33 & 3.31 & -13.13 \\
\hline & & 40 & 3.54 & 0.13 & 9.33 & 8.58 & -8.76 & 8.44 & -10.52 \\
\hline & & 60 & 5.19 & 0.21 & 13.28 & 12.58 & -5.59 & 12.38 & -7.30 \\
\hline & & 80 & 8.54 & 0.49 & 21.65 & 20.69 & -4.62 & 20.37 & -6.31 \\
\hline & & 100 & 10.56 & 1.11 & 26.94 & 25.59 & -5.28 & 25.18 & -6.98 \\
\hline & & 120 & 13.61 & 1.90 & 33.15 & 32.98 & -0.51 & 32.46 & -2.14 \\
\hline & \multirow{6}{*}{3} & 20 & 1.42 & 0.18 & 5.71 & 5.16 & -10.63 & 5.04 & -13.29 \\
\hline & & 40 & 3.61 & 0.15 & 14.41 & 13.12 & -9.82 & 12.81 & -12.47 \\
\hline & & 60 & 5.29 & 0.19 & 20.63 & 19.23 & -7.29 & 18.78 & -9.88 \\
\hline & & 80 & 8.71 & 0.53 & 32.89 & 31.66 & -3.89 & 30.91 & -6.39 \\
\hline & & 100 & 10.83 & 1.24 & 38.37 & 39.37 & 2.53 & 38.44 & 0.18 \\
\hline & & 120 & 14.11 & 2.38 & 45.94 & 51.29 & 10.43 & 50.08 & 8.27 \\
\hline
\end{tabular}

Deviation percent $(\%)=\frac{P_{\text {Calculated }}-P_{\text {Picopress }}}{P_{\text {Calculated }}} \times 100$

The obtained results in Table 1 confirm that there are significant deviations when applying Laplace's equation for two and three layers bandaging ranging \pm 0.68 to $\pm 15.64 \%$. However, Jawad Al Khaburi developed this Eq. (4) to include the increase in limb circumference due to multilayer bandaging; this equation has decreased the deviation range to be $\pm 0.07: \pm 12.55 \%$ as illustrated in the following Eqs (4) and (5) [34]:

$\mathrm{P}=\sum_{i=1}^{n} \frac{\mathrm{T}_{\mathrm{i}}\left(\mathrm{D}_{\mathrm{i}}+\mathrm{t}_{\mathrm{i}}\right)}{0.5 * \mathrm{~W}_{\mathrm{i}} * \mathrm{D}_{\mathrm{i}}^{2}+\mathrm{W}_{\mathrm{i}} * \mathrm{t}_{\mathrm{i}}\left(\mathrm{D}_{\mathrm{i}}+\mathrm{t}_{\mathrm{i}}\right)} * 0.0075$
Where $\mathrm{D}_{\mathrm{i}}=D+\sum_{i=1}^{n} 2 \mathrm{t}_{\mathrm{i}-1}$

Results of Table 2 conclude that the deviation when applying Laplace's equation for mid-calf position is ranging \pm 0.27 to $\pm 13.14 \%$, while the deviation range of Al Khaburi's equation is \pm 0.14 to $\pm 11.04 \%$.

\subsection{Stress-relaxation test for long and short-stretch WCBs}

Figures 12 and 13 illustrate that CO-PA-PU LSB recovered approximately $99 \%$ of its original length after stress-relaxation; this elastic recovery gives beneficial options through the optimum elasticity when applying the LSB while Cotton SSB recovered only $93 \%$ of its gauge length after 5 days of cyclic 


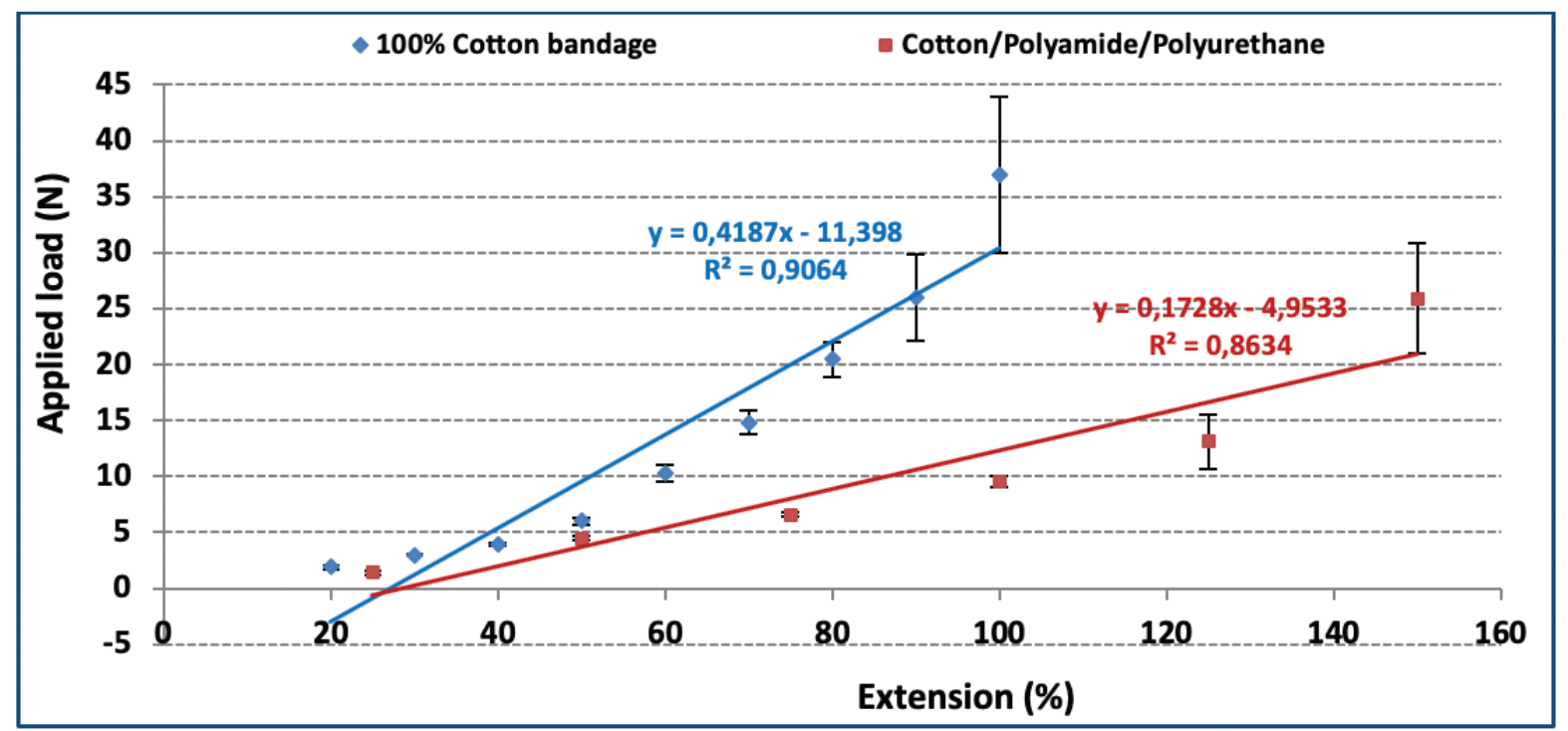

Figure 6. Effect of bandage extension on applied tension for short-stretch cotton and long-stretch Cotton/Polyamide/Polyurethane bandages.

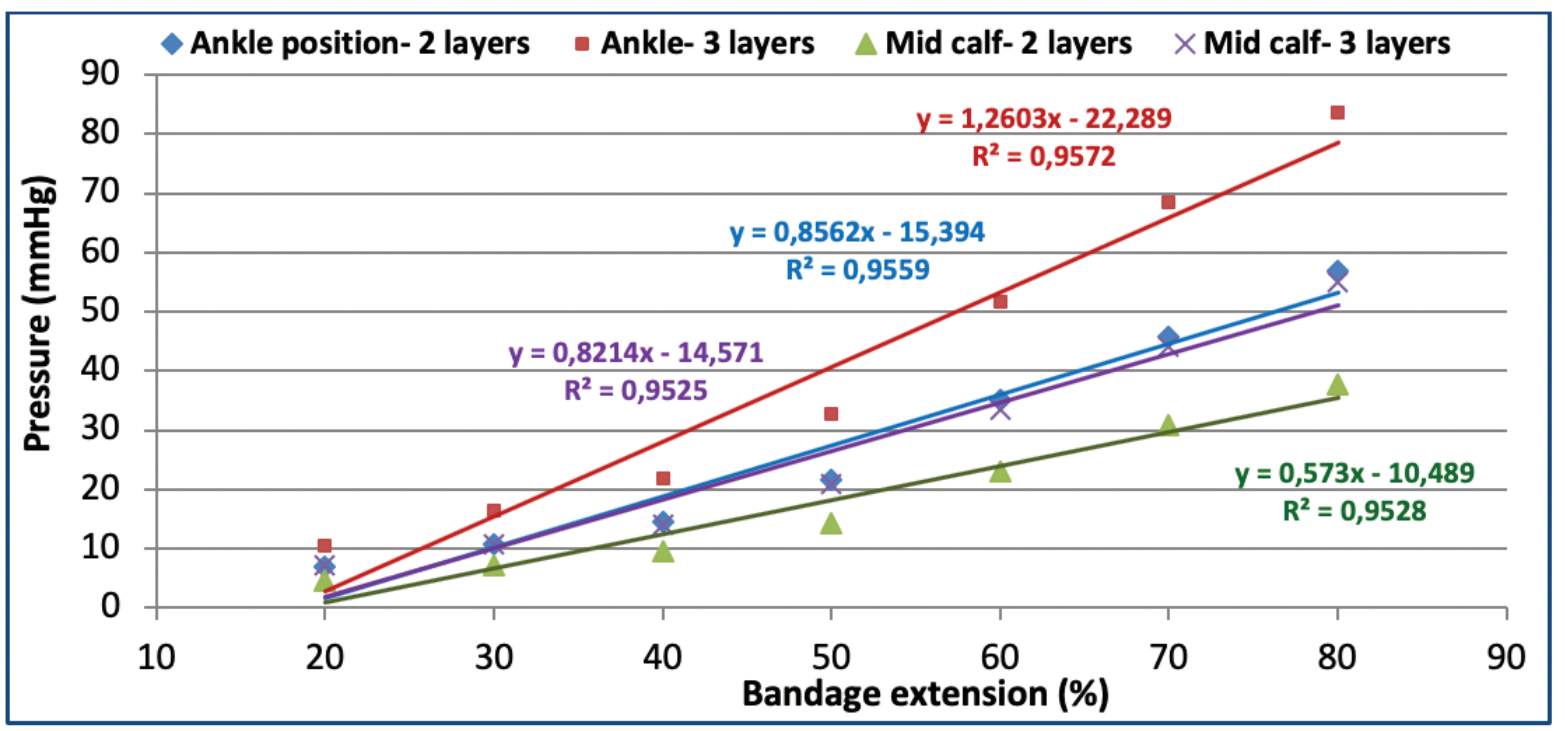

Figure 7. Effect of bandage extension on corresponding pressure for short-stretch cotton bandage.

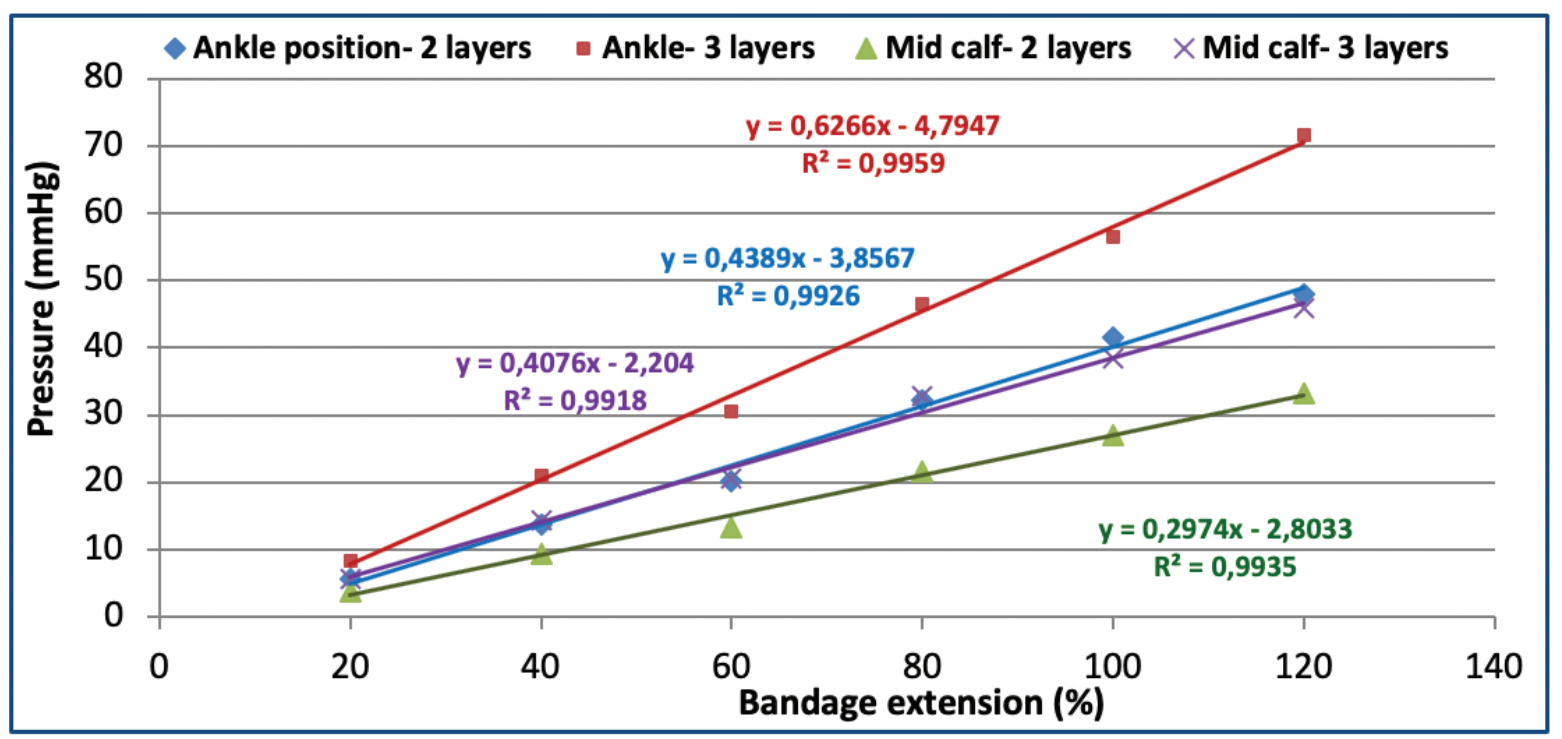

Figure 8. Effect of bandage extension on resultant pressure for Cotton/Polyamide/Polyurethane woven compression bandage. 


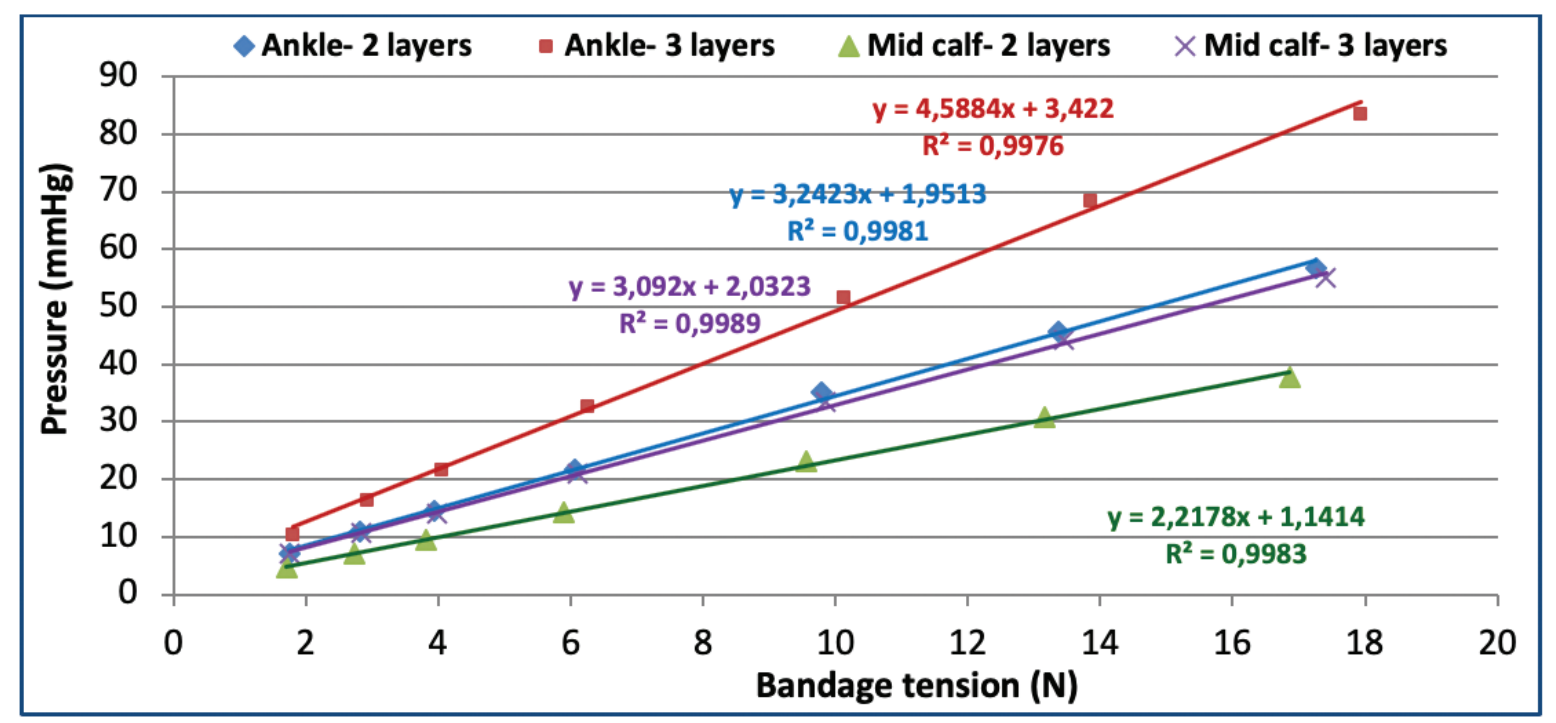

Figure 9. Effect of bandage tension on corresponding pressure for short-stretch Cotton bandage.

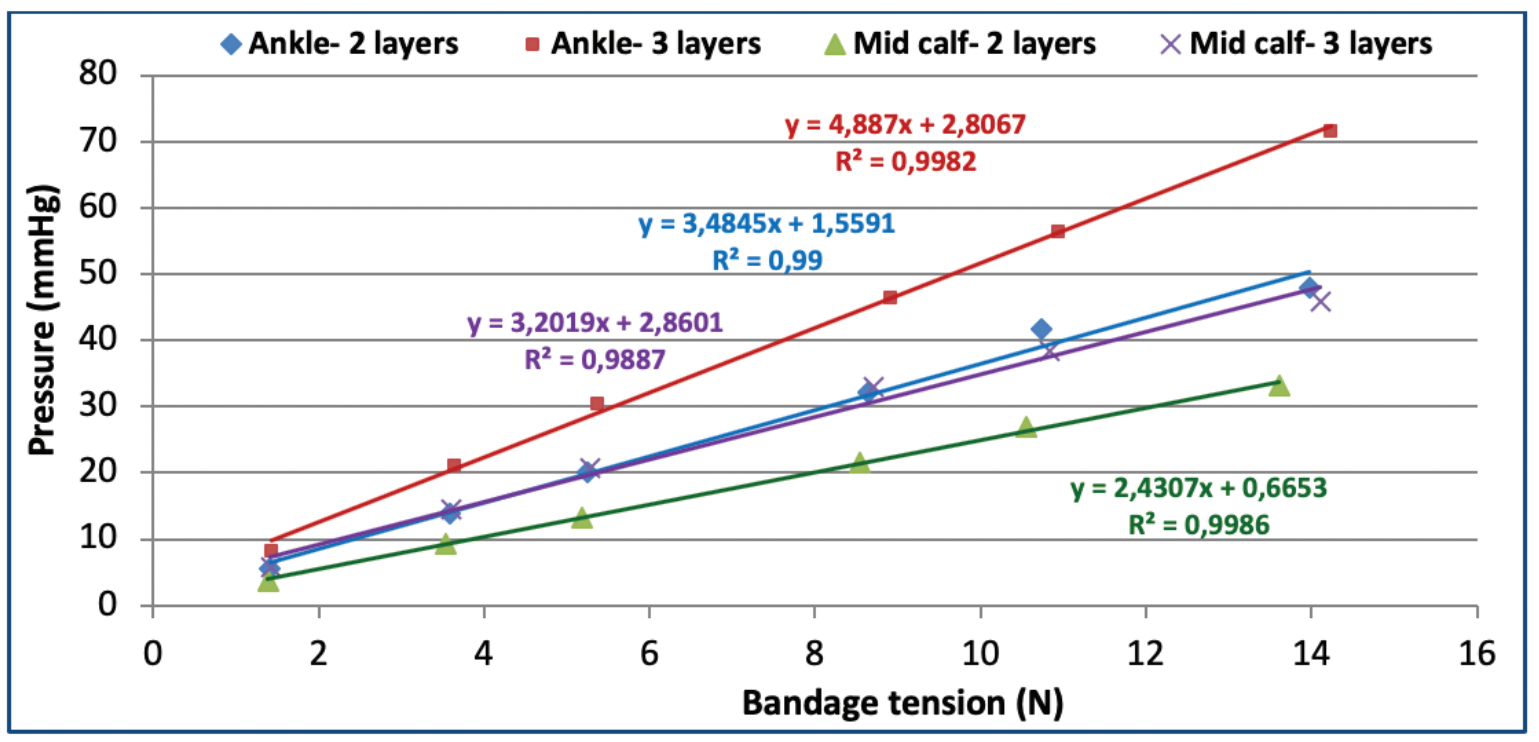

Figure 10. Effect of bandage tension on corresponding pressure for Cotton/Polyamide/Polyurethane woven compression bandage.

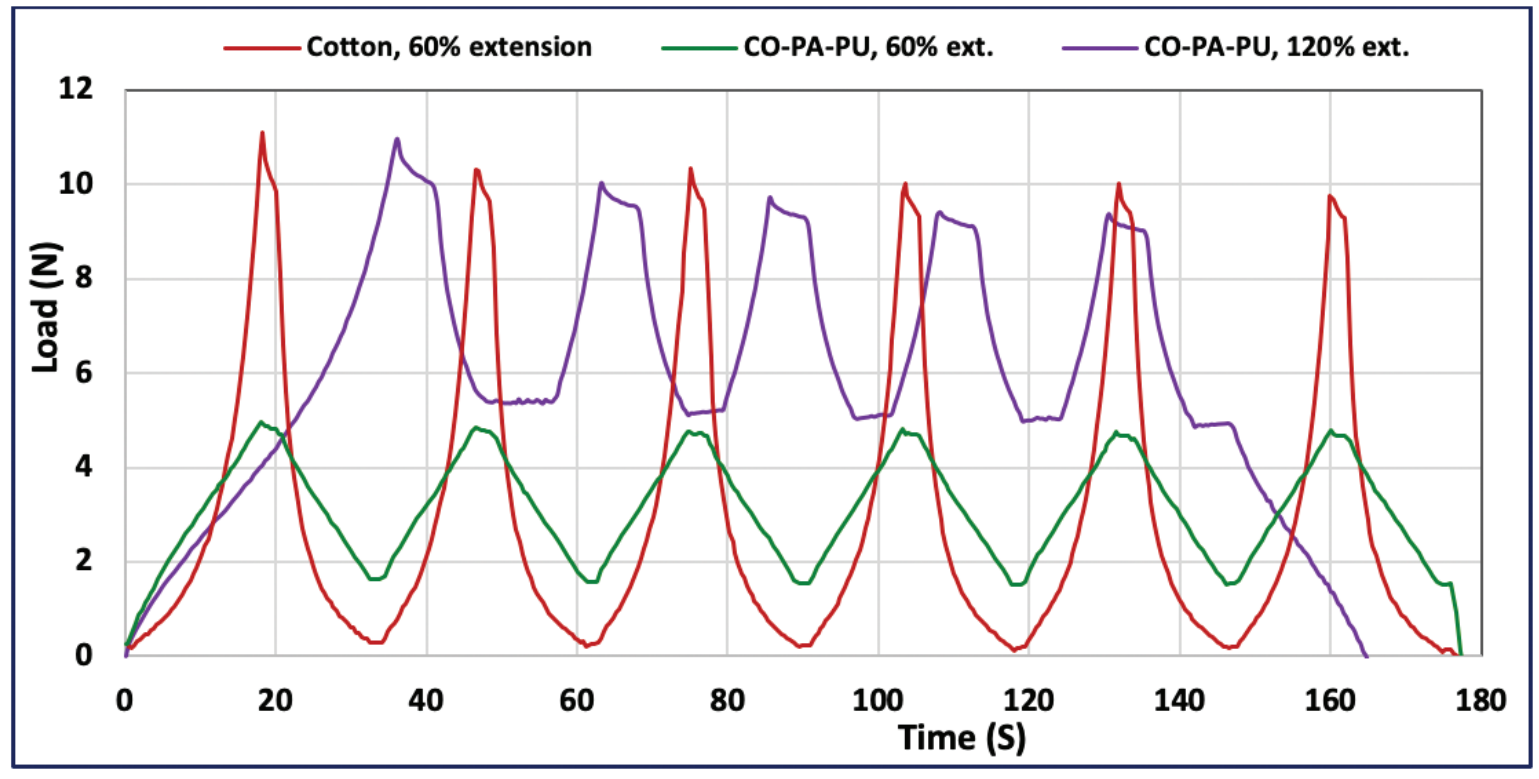

Figure 11. Effect of cyclic loading on bandage applied tension. 


\begin{tabular}{|c|c|c|}
\hline Bandage test results & CO-PA-PU LSB & Bleached Cotton SSB \\
\hline $\begin{array}{c}\text { Original gauge length } 5 \\
\mathrm{~cm}\end{array}$ & & \\
\hline $\begin{array}{c}\text { After } 5 \text { days of cyclic } \\
\text { load-relaxation }\end{array}$ & & \\
\hline
\end{tabular}

Figure 12. Effect of stress-relaxation on elastic recovery of long and short-stretch woven bandages.

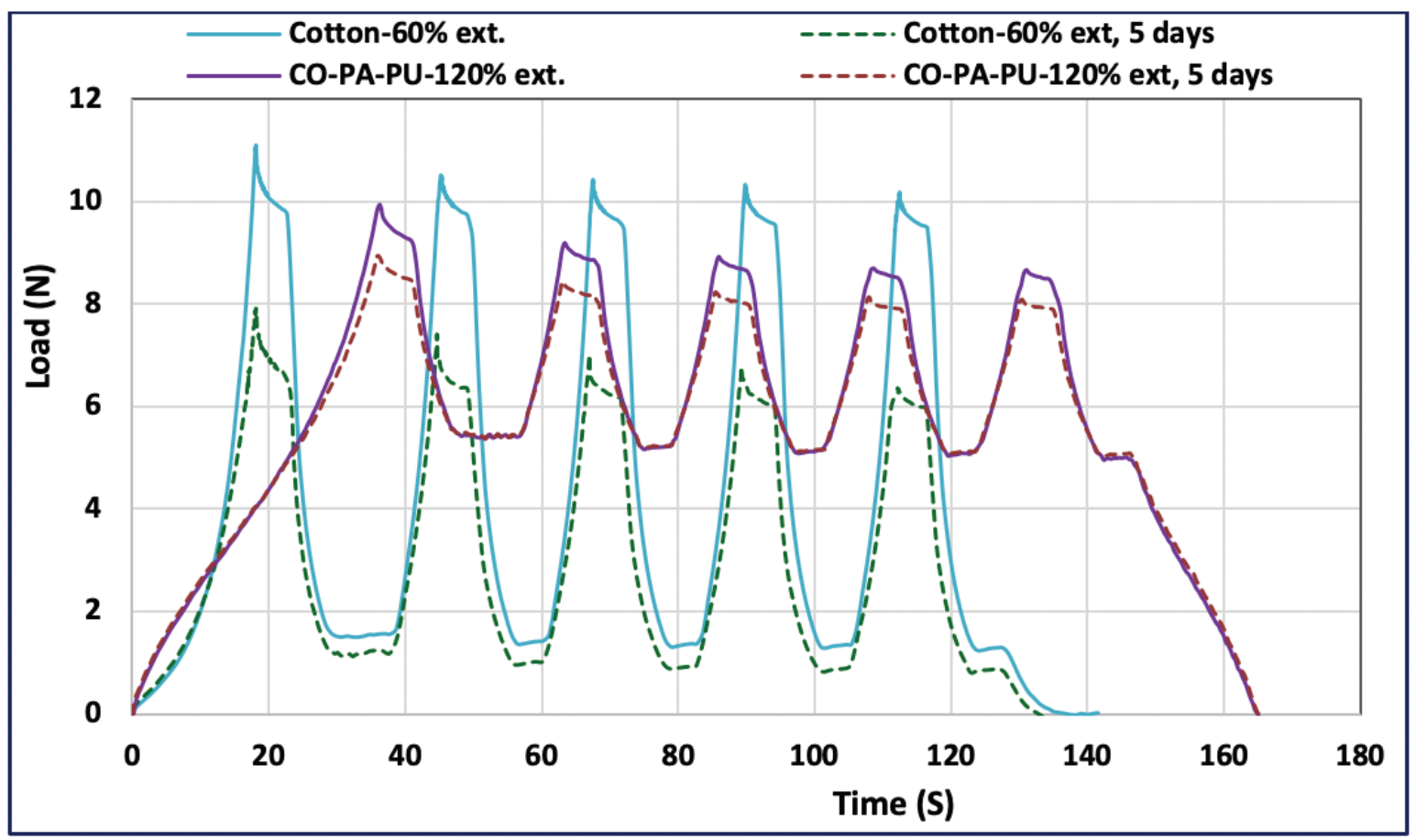

Figure 13. Effect of cyclic loading on applied load by long and short-stretch woven bandages.

load-relaxation. Even when this LSB was wrapped on the human leg for 5 days ( $12 \mathrm{~h} /$ day), there was very little residual deformation after a longer treatment time. On the contrary, when Cotton WCBs used for the same time, there was a significant residual deformation, see Figure 12. Moreover, it lost approximately $28.6 \%$ of its activity, as confirmed by the cyclic loading-unloading tests, see Figure 13.

\section{Conclusion}

CO-PA-PU and $100 \%$ Cotton WCBs were selected to compare long- and short-stretch WCBs in resting and working actions. The short-stretch cotton bandage had $10.3 \mathrm{~N}$ at $60 \%$ extension, whereas long-stretch CO-PA-PU achieved only $5.31 \mathrm{~N}$, these LSB should be extended to $120 \%$ to achieve $14.15 \mathrm{~N}$. So that
SSB can be applied for severe leg ulcers and edema cases that need high pressure ranges $50-70 \mathrm{mmHg}$ depending on bandage extension and number of layers. Cyclic loading-unloading test confirmed that short-stretch WCB lost approximately $28.6 \%$ of its activity, whereas LSB lost only $10.05 \%$ after 5 days of application. The maximum deviations between Picopress and calculated pressure by Laplace's law were $15.64 \%$ and $12.55 \%$ by Al-Khaburi equation. These deviation values appeared only at the highest pressure values using three layers bandaging on ankle position.

\section{Acknowledgments}

The authors acknowledge the assistance and support by (SGS project 21303), Technical University of Liberec, Czech Republic. 


\section{References}

[1] Aboalasaad, A. R. R., Sirková, B. K. (2019). Analysis and prediction of woven compression bandages properties. The Journal of the Textile Institute, 110(7), 1085-1091.

[2] Kaur, B. (2018). Bandages: Short-stretch vs long-stretch. [Online]. June 25, 2018.

[3] De Carvalho, M. R., de Oliveira, B. G. (2017). Compression therapy for venous leg ulcers: a systematic review of the literature. Enfermería Global, 16(1), 574-593.

[4] Nair, B. (2014). Compression therapy for venous leg ulcers. Indian Dermatology Online Journal, 5(3), 378-382.

[5] Caprini, J. A., Partsch, H., Simman, R. (2012). Venous ulcers. Journal of the American College of Clinical Wound Specialists, 4(3), 54-60.

[6] O'Donnell, T. F., Passman, M. A., Marston, W. A., Ennis, W. J., Dalsing, M., et al. (2014). Management of venous leg ulcers: Clinical practice guidelines of the society for vascular surgery ${ }^{\circledR}$ and the American venous forum. Journal of Vascular Surgery, 60(2), 3S-59S.

[7] Partsch, H., Mortimer, P. (2015). Compression for leg wounds. British Journal of Dermatology, 173(2), 359-369.

[8] Nelson, E. A., Hillman, A., Thomas, K. (2014). Intermittent pneumatic compression for treating venous leg ulcers. Cochrane Database of Systematic Reviews, 5.

[9] Agale, S. V. (2013). Chronic leg ulcers: Epidemiology, aetiopathogenesis, and management. Hindawi Publishing Corporation, Ulcers, Article ID 413604.

[10] Zuther, J. (January 12, 2012). The role of short-stretch bandages in the management of Lymphedema. Online. May 2, 2019.

[11] Sikka, M. P., Ghosh, S., Mukhopadhyay, A. (2014). The structural configuration and stretch property relationship of high stretch bandage fabric. Fibers and Polymers, 15(8), 1779-1785.

[12] Aboalasaad, A. R. R., Sirková, B. K. (2017). Analysis and prediction of compression bandages tension. Ph. D. Students Day, 6. Liberec, Czech Republic.

[13] Jouanny, S. (March 20, 2018). The difference between short-stretch and long-stretch bandages. Web site: https:// www.mylymph.com/2018/03/20/difference-between-shortlong-stretch-bandages/. [Online]. April 10, 2019.

[14] Mosti, G., Partsch, H. (2019). A wearable compression device to normalise calf muscle pump function in chronic venous insufficiency for each postural position. European Journal of Vascular and Endovascular Surgery. doi: 10.1016/j.ejvs. 20.

[15] Langer, V. (2014). Compression therapy for leg ulcers. Indian Dermatology Online Journal, 5(4), 533-534.

[16] Partsch, H., Menzinger, G., Mostbeck, A. (1999). Inelastic leg compression is more effective to reduce deep venous refluxes than elastic bandages. Dermatologic Surgery, 25(9), 695-700.

[17] Moody, M. (1999). Comparison of Rosidal K and SurePress in the treatment of venous leg ulcers. British Journal of Nursing, 8(6), 345-355.

[18] Partsch, H. (2005). The Static Stiffness Index - a simple method to assess the elastic property of compression material in vivo. Dermatologic Surgery, 31(6), 625-630.
[19] Polignano, R., Boneado, P., Gasbarro, S., Allegra, C. (2004). A randomised controlled study of four-layer compression versus Unna's Boot for venous ulcers. Journal of Wound Care, 13(1), 21-24.

[20] Rooke, T. W., et al. (2011). ACCF/AHA focused update of the guideline for the management of patients with peripheral artery disease (updating the 2005 guideline): a report of the American College of Cardiology Foundation/American Heart Association Task Force on Practice Guidelines.

[21] Meah, Y. S., et al. (2016). Wound care in home-based settings. In: Hayashi, J., Leff, B. (Eds.). Geriatric homebased medical care. Springer (Cham), pp. 195-236.

[22] Attaran, R. R., Ochoa Chaar, C. I. (2017). Compression therapy for venous disease. Phlebology, 32(2), 81-88.

[23] ISO, E. (1999). 13934-1: 1999 Textiles-tensile properties of fabrics-part 1: determination of maximum force and elongation at maximum force using the strip method. European Committee for Standardisation. International Organization for Standardization.

[24] Kumar, B., Das, A., Alagirusamy, R. (2013). An approach to examine dynamic behavior of medical compression bandage. Journal of the Textile Institute, 104(5), 521-529.

[25] Aboalasaad, A. R., Kolčavová, B. S., Berk, G. G. (December 2018). Effect of compression bandages on muscle's behavior. IOP Conference Series: Materials Science and Engineering, 460(1), 012034.

[26] Rimaud, D., Convert, R., Calmels, P. (2014). In vivo measurement of compression bandage interface pressures: the first study. Annals of Physical and Rehabilitation Medicine, 57(6-7), 394-408.

[27] Kwon, C., Hegarty, M., Oxenham, W., Thoney-Barletta, K., Grant, E., et al. (2018). An indirect testing approach for characterizing pressure profiles of compression bandages and hosiery. The Journal of the Textile Institute, 109(2), 256-267.

[28] Schuren, J., Mohr, K. (2008). The efficacy of Laplace's equation in calculating bandage pressure in venous leg ulcers. Wounds UK, 4(2), 38-42.

[29] Kumar, B., Das, A., Alagirusamy, R. (2013). Study on interface pressure generated by a bandage using in vitro pressure measurement system. The Journal of the Textile Institute, 104(12), 1374-1383

[30] Anand, S. C., Govarthanam, K. K., Gazioglu, D. (2013). A study of the modelling and characterisation of compression garments for hypertrophic scarring after burns. Part 1: Modelling of compression garments. Journal of the Textile Institute, 104(7), 661-667.

[31] Das, A., Alagirusamy, R., Goel, D., Garg, P. (2010). Internal pressure profiling of medical bandages.. The Journal of the Textile Institute, 101(6), 481-487.

[32] Partsch, H., Clark, M., Mosti, G., Steinlechner, E., Schuren, J., et al. (2008). Classification of compression bandages: practical aspects. Dermatologic Surgery, 34(5), 600-609.

[33] Aboalasaad, A. R., Sirková, B., Ahmad, Z. (2019). Influence of tensile stress on woven compression bandage structure and porosity. Autex Research Journal (published online ahead of print). doi: 10.2478/aut-2019-0027

[34] Al Khaburi, J., Dehghani-Sanij, A., Nelson, A., Hutchinson, J. (2012). Effect of bandage thickness on interface pressure applied by compression bandages. Medical Engineering \& Physics, 34(3), 378-385. 